\title{
A TECNOLOGIA DE OZONIZAÇÃO NO TRATAMENTO DE EFLUENTES DE CURTUME
}

\author{
ANDRIOLI, E., MELLA, B. e GUTTERRES, M.
}

Universidade Federal do Rio Grande do Sul, Departamento de Engenharia Química, Laboratório de Estudos em Couro e Meio Ambiente (LACOURO)

E-mail para contato: andrioli@enq.ufrgs.br, bianca@enq.ufrgs.br e mariliz@enq.ufrgs.br

RESUMO - Durante o processamento de peles em couro são utilizadas grandes quantidades de água, gerando, consequentemente, um grande volume de efluente a ser tratado. Estes efluentes apresentam elevada carga orgânica, sulfetos, cromo, corantes, óleos, tensoativos, recurtentes, taninos, entre outros contaminantes, o que torna difícil o seu tratamento e adequação aos padrões de lançamento deste no meio receptor. Diversos estudos estão sendo realizados na intenção de aprimorar o tratamento destes efluentes, possibilitando, inclusive, o reuso do efluente tratado. Dentre as diversas tecnologias estudadas, está a ozonização, destacando-se por ser considerada uma tecnologia limpa e bastante promissora. O ozônio é um gás com alto poder oxidante, sendo por isso aplicado como uma tecnologia capaz de reduzir e/ou remover inúmeros parâmetros de poluição. Assim, este trabalho realizará um estudo da possibilidade do uso do ozônio no tratamento de efluentes de curtume.

\section{INTRODUÇÃO}

O processo de curtimento de peles no Brasil e no mundo é de grande importância econômica. O Brasil possui o segundo maior rebanho mundial, apresentando aproximadamente 210 milhões de cabeças de gado e possui o maior rebanho comercializável do mundo. O País é também o segundo maior produtor e exportador de couros e mira a excelência com investimentos, qualificação e tecnologia (ABQTIC, 2013). Por este motivo, a indústria mundial do couro tem dado crescente atenção e vem empreendendo esforços para tratar os efluentes líquidos e dar uma destinação adequada aos lodos e resíduos gerados nos processos (Gutterres e Mella, 2014).

O processamento do couro consiste em transformar a pele (verde ou salgada) em couro, dando acabamento final de acordo com o artigo de couro desejado. Para tal, a pele passa por diversas etapas de processamento, com adições de água e produtos químicos às peles processadas em fulões, intercaladas por pesagens, lavagens e operações mecânicas.

De acordo com IUE, estudo publicado em 2008 pela IULTCS, os curtumes utilizam cerca de 12 a $37 \mathrm{~m}^{3}$ de água por tonelada de pele processada na produção do couro, porém estes 
valores podem ser superiores em função das águas de lavagem empregadas entre as operações nos fulões. Para Suthanthararajan et al. (2004) aproximadamente $30 \mathrm{~m}^{3}$ de efluentes são gerados por tonelada de pele durante o processamento do couro.

Os efluentes de curtume geralmente são caracterizados pela elevada carga orgânica e inorgânica. Além disso, estes efluentes contêm alta intensidade de cor devido à presença de corantes, produtos químicos residuais e taninos, utilizados em operações de curtimento e acabamento, além de outros compostos que são de difícil eliminação no tratamento convencional de efluentes. Grande parte destes produtos e compostos é aproveitada, ou seja, é absorvida e fixada nas peles e couros, o que costuma-se chamar de esgotamento dos banhos em fulões, porém uma parcela destes compostos acaba sendo descartada nos efluentes. A Tabela 1 apresenta os principais processos e produtos utilizados no processamento do couro.

Tabela 1 - Principais processos e produtos utilizados no processamento do couro

Etapa

Conservação

Remolho

Depilação e caleiro

Desencalagem

Purga

Píquel

Curtimento

Desacidulação

Recurtimento

Tingimento

Engraxe

Acabamento

\section{Produtos Utilizados}

Sal (cloreto de sódio), agentes conservantes microbicidas (TCMTB:

2 (tiocianometiltio)- benzotiazol; NOIT: 2-N-octil-4-isotiazolin-3-

ona; CMP: 4-cloro-3-metil fenol sal sódico; OPP: Orto fenil fenol sal sódico; MBT: Metileno bistiocianato; TBP: Tri bromo fenol,

TCMTB (2-tiocianometiltiobenzotiazol))

Sais, álcalis, ácidos, tensoativos, enzimas, bactericidas

Cal e sulfeto de sódio, aminas, enzimas

Sais amoniacais, bissulfito de sódio ou ácidos fracos

Enzimas proteolíticas (pancreáticas, microbianas)

Ácidos, especialmente, sulfúrico e fórmico

Sais de cromo, taninos vegetais, biocidas e outros curtentes

Bicarbonato de sódio, formiato de sódio, taninos neutralizantes

Sais de $\mathrm{Cr}, \mathrm{Al}, \mathrm{Zr}$, taninos vegetais e sintéticos, aldeídos

Corantes e alguns auxiliares, ácidos para a fixação do corante

Óleos, agentes tensoativos

Polímeros, reticulantes, solventes, cargas, pigmentos

Dentre as substâncias que cumprem as funções acima, muitas são de uso restrito na indústria coureiro, calçadista e de produtos de couro por uma série de razões que incluem a segurança de consumidores e trabalhadores, e os aspectos ambientais como, por exemplo, a toxicidade das águas e potencial de bioacumulação. A lista de substâncias químicas restritas em artigos de vestuário e calçado inclui: corantes azóicos específicos, cromo hexavalente, pentaclorofenol (PCB), cádmio e seus compostos, formaldeído, alcanos clorados (C10-C13), ftalatos, fenóis, compostos orgânicos voláteis (COV). Alquilfenóis etoxilados, por exemplo, são surfactantes não iônicos empregados em produtos químicos para couros. Esses produtos de difícil degradação podem não ser removidos nas estações de tratamento e serem descartados nos 


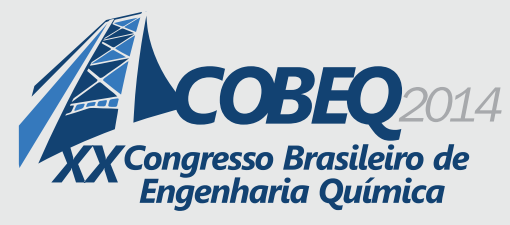

19 a 22 de outubro de 2014

Florianópolis/SC

mananciais de águas. Corantes do tipo azóico são os mais comumente empregados na indústria têxtil e de couro brasileiro. Estima-se que entre 90 a $95 \%$ dos couros produzidos em todo mundo são tingidos com corantes azóicos. As principais fontes de compostos orgânicos voláteis no acabamento são encontradas em produtos como solventes, niveladores, tensoativos, aminas, reticulantes, tops e lacas. Atualmente, usa-se como princípio ativo de microbicidas o TCMTB (2tiocianometiltiobenzotiazol), como alternativa para substituir o PCP e derivados fenólicos na indústria do couro. Nos últimos 100 anos, o formaldeído tem sido um produto muito usado na indústria do couro nas etapas de curtimento, recurtimento e acabamento. Em materiais de couro, o formaldeído é usado como estabilizador (preventivo), como conservante antes do curtimento, em pré-curtimento para obter o couro wet-white, em matérias-primas básicas na síntese dos taninos sintéticos e em acabamento com algum tipo de resina (Wegner, 2004; Fuck e Gutterres, 2008; INESCOP, 2011). Segundo Gutterres (2011), sais curtentes de cromo são atualmente empregados em cerca de $80 \%$ dos casos e somente a forma trivalente do cromo é usada nos processos de curtimento. Estas substâncias também são contaminantes dos efluentes, o que acarreta no aumento da sua toxicidade, necessitando, por isso, de tratamento adequado para sua remoção efetiva.

A indústria de curtimento é conhecida por ser um dos principais setores da economia em muitos países, por isso há uma crescente preocupação ambiental em relação ao lançamento de vários poluentes recalcitrantes em efluentes de curtume. Os processos biológicos são atualmente conhecidos como os mais ambientalmente corretos, mas ineficazes para a remoção de compostos orgânicos persistentes e micropoluentes em águas residuais de curtume, o que justifica tecnologias emergentes, tais como processos oxidativos avançados e processos com membranas, a serem testados associados ao tratamento biológico (Lofrano et al., 2013).

A utilização do ozônio é uma importante tecnologia aplicada tanto ao tratamento de águas de abastecimento como residuais. Devido ao seu elevado potencial de oxidação, é aplicado como uma tecnologia capaz de reduzir e/ou remover inúmeros poluentes ambientais.

A ozonização tem sido citada na literatura como sendo uma tecnologia de tratamento bastante promissora. Inúmeras aplicações em escala real já podem ser encontradas tanto na área de tratamento de águas de abastecimento como em tratamento de efluentes industriais, geralmente associada a processos biológicos (Assalin e Durán, 2006). A ozonização vem sendo estudada no tratamento de diversos efluentes, como por exemplo, na remoção de micropoluentes (organoclorados) (Derco et al., 2012), na remoção de traços de antibióticos (norfloxacina, ofloxacina, roxitromicina e azitromicina) (Liu et al., 2014), e até mesmo na degradação de pesticidas em sementes (Bourgin et al., 2013).

Os avanços das tecnologias alternativas para a remediação de efluentes, dentre elas os processos oxidativos avançados, vêm contribuindo para o desenvolvimento do controle da poluição ambiental. De modo geral, o processo de ozonização é eficiente, principalmente na descoloração, remoção de compostos refratários e aumento da biodegradabilidade de diferentes tipos de efluente. O grande desafio para tornar a ozonização uma tecnologia de remediação mais abrangente é atingir maiores taxas de mineralização, obtendo-se alta eficiência de remoção da carga orgânica do efluente. Com este propósito, a ozonização catalítica, a nanocatálise 
heterogênea, bem como a combinação com processos biológicos, são apresentados na literatura como a tendência atual na aplicação de ozônio na remediação de efluentes (Almeida et al., 2004).

Assim, o objetivo deste trabalho é fazer um levantamento sobre a aplicação da ozonização no tratamento de efluentes de curtume.

\section{OZONIZAÇÃO}

O ozônio é capaz de reagir com uma numerosa classe de compostos orgânicos, devido, principalmente, ao seu elevado potencial de oxidação, superior ao de compostos reconhecidamente oxidantes, como $\mathrm{H}_{2} \mathrm{O}_{2}$ e o próprio cloro. No entanto, muitos compostos orgânicos como os organoclorados reagem lentamente com o ozônio molecular. Em determinadas condições o ozônio leva à formação de radicais hidroxilas, cujo potencial de oxidação é ainda mais elevado, podendo ser mais efetivo no tratamento de certos compostos recalcitrantes. Os processos que implicam na formação do radical hidroxila são denominados Processos Oxidativos Avançados (POAs) (Almeida et al., 2004). O ozônio é um gás instável de alto poder oxidante. Essas duas características o tornam atrativo para a desinfecção de esgotos domésticos. A instabilidade desse gás é uma característica desejável porque quando o efluente é lançado no meio ambiente não haverá residual de oxidante que possa ser danoso à biota aquática. $\mathrm{O}$ alto poder oxidante é desejável porque diminui muito as concentrações e o tempo necessário para a desinfecção. Assim, com o tempo de contato e as concentrações reduzidas, haverá economia na construção e operação das instalações (Bassani, 2003).

O ozônio pode reagir com a carga orgânica presente no efluente por duas maneiras: (a) reação direta (Equação 1), um processo que é altamente seletivo para aromáticos e bastante lento; (b) reação indireta através de radicais $\mathrm{OH}$ (Equações 2 e 3), que vem da fragmentação da espécie $\mathrm{HO}_{3}{ }^{\bullet}$ :

$$
\begin{aligned}
& \mathrm{O}_{3}+\mathrm{M} \rightarrow \mathrm{O}^{\bullet-}+\mathrm{M}^{+} \\
& \mathrm{O}^{\bullet-}+\mathrm{M}^{+} \rightarrow \mathrm{HO}_{3}^{\bullet} \\
& \mathrm{HO}_{3}^{\bullet}+\mathrm{O}_{2} \rightarrow \mathrm{OH}^{\bullet}
\end{aligned}
$$

Pode ser notado que o íon ozonídeo $\left(\mathrm{O}_{3}{ }^{\bullet}\right)$, necessário para o caminho indireto, é também um produto da reação do ozônio com $\mathrm{OH}^{-}$. Consequentemente, um meio básico promove a geração de $\mathrm{O}_{3}{ }^{\bullet-}$ pelo mesmo caminho que a presença de matéria orgânica $(\mathbf{M})$ na reação 1 (Equação 1) (Pérez et al., 2002).

No caso de corantes, ozônio pode eficazmente descolorir o corante presente em águas residuais, quebrando as duplas ligações $(-\mathrm{N}=\mathrm{N}-)$ conjugadas associadas com o corante. $\mathrm{O}$ ozônio cliva as ligações insaturadas das moléculas aromáticas encontradas em substâncias húmicas, os grupos cromóforos de corantes e outros compostos pigmentados, reduzindo, assim, a 
cor (Alaton et al., 2002; Srinivasan et al., 2009).

A oxidação de compostos orgânicos e inorgânicos durante a ozonização pode ocorrer por meio do ozônio ou de radicais hidroxila, ou uma combinação dos mesmos. A via de oxidação é determinada pela relação entre o ozônio e as concentrações de radicais hidroxila, e a cinética correspondente. O ozônio é um eletrófilo com uma elevada seletividade. As reações do ozônio com compostos inorgânicos relevantes da água são geralmente rápidas e ocorrem por uma reação de transferência de átomo de oxigênio. Micropoluentes orgânicos são oxidados com o ozônio seletivamente. $\mathrm{O}$ ozônio reage principalmente com ligações duplas, sistemas aromáticos ativados e aminas não protonadas. Em geral, os grupos doadores de elétrons favorecem as reações de oxidação por ozônio, enquanto grupos receptores de elétrons reduzem as taxas de reação. A reação dos radicais hidroxila, com a maioria dos compostos orgânicos e inorgânicos é praticamente controlada por difusão (von Gunten, 2003).

\section{OZONIZAÇÃO NO TRATAMENTO DE EFLUENTES DE CURTUME}

Os efluentes de curtume contêm muitos nutrientes, que favorecem o tratamento biológico, mas também muitos contaminantes, que podem prejudicar o tratamento. $\mathrm{O}$ descarte sem tratamento ou o tratamento pouco eficiente destes efluentes pode trazer riscos ao meio aquático, e consequentemente, efeitos na saúde humana. Assim, o estudo e a aplicação de novas técnicas ao tratamento de efluentes vêm crescendo constantemente. Neste contexto, a aplicação do ozônio no tratamento de efluentes de curtumes está sendo estudada por diversos autores, com a obtenção de bons resultados na remoção de DQO, DBO, sólidos suspensos totais (SST), carbono orgânico total (COT), cor, Nitrogênio Total Kjeldahl (NTK), etc., como pode ser observado na Tabela 2.

Tabela 2 - Aplicações de ozonização em efluentes de curtume

\begin{tabular}{|c|c|c|}
\hline Efluente & $\begin{array}{c}\text { Tipo de } \\
\text { Equipamento/Detalhes } \\
\text { Experimentais }\end{array}$ & $\begin{array}{c}\text { Eficiências de Remoção/Melhores } \\
\text { Condições }\end{array}$ \\
\hline $\begin{array}{l}\text { Efluente de curtume previamente } \\
\text { coagulado/floculado } \\
\text { (Schrank } \text { et al., 2004) }\end{array}$ & $\begin{array}{l}\text { pHs testados }=3,7,11 \\
\text { Vazão } \mathrm{O}_{3}=2,6 \mathrm{~g} \mathrm{O}_{3} / \mathrm{h} \\
\text { t: } 60 \mathrm{~min}\end{array}$ & $\begin{array}{c}\text { Em } \mathrm{pH}=11 \\
17 \% \text { de } \mathrm{DQO} \\
12 \% \text { de COT } \\
24 \% \text { de DBO }\end{array}$ \\
\hline Efluente de curtume & & $\begin{array}{c}6 \% \text { de DQO } \\
t=5 \mathrm{~min} \\
\text { Vazão } \mathrm{O}_{3}=42,8 \mathrm{mg} / \mathrm{min}\end{array}$ \\
\hline Efluente tratado biologicamente & & $\begin{array}{c}30 \% \text { de DQO } \\
\mathrm{t}=5 \mathrm{~min} \\
\text { Vazão } \mathrm{O}_{3}=42,8 \mathrm{mg} / \mathrm{min}\end{array}$ \\
\hline
\end{tabular}


Efluente proveniente da etapa de caleiro

Bouzid et al. (2008)
$\mathrm{Em} \mathrm{pH}=8$

$55 \%$ de DQO

$\mathrm{Em} \mathrm{pH}=12$

$16 \%$ de DQO

3,5 g de ozônio são necessários para oxidar

$1 \mathrm{~g}$ de sulfeto

$>90 \%$ de DQO

$>85 \%$ de $\mathrm{SST}$

$>85 \%$ de NTK

93\% de Surfactantes

$24 \%$ de cor

$20 \%$ de DQO

pHs testados: 4,7,11

Vazões de $\mathrm{O}_{3}$ testadas $=$ $2 \times 10^{-3}, 4 \times 10^{-3}, 6 \times 10^{-3}$ $\mathrm{m}^{3} / \mathrm{min}$

Em tempos de: 20-120 min

Preethi et al. (2009)

pHs testados 4, 7, 9, 11

Vazão de $\mathrm{O}_{3}=1,6 \mathrm{mgL} / \mathrm{L}$

Tempos de: 10-20-30-40$50 \mathrm{~min}$

Efluente de curtume tratado biologicamente

Dose aplicada $\mathrm{O}_{3}=150 \mathrm{~g} / \mathrm{m}^{3}$

t: $60 \mathrm{~min}$
$92 \%$ de DQO

$\mathrm{Em} \mathrm{pH}=11$

$\mathrm{t}=80 \mathrm{~min}$

Vazão $\mathrm{O}_{3}=6 \times 10^{-3} \mathrm{~m}^{3} / \mathrm{min}$

$>97 \%$ de cor

$\mathrm{t}=20 \mathrm{~min}$

$\mathrm{pH}=7$
Srinivasan et al. (2009)

Di Iaconi et al. (2010)

Efluente pré-alcalinizado

Houshyar et al. (2012)

97\% de DQO

$96 \%$ de TSS

$91 \%$ de NTK

$98 \%$ de surfactantes

$96 \%$ de cor

$88 \%$ de DQO

$93 \%$ a cor do efluente

Observando-se a Tabela 2, pode-se concluir que o uso de ozônio mostra-se com um método promissor ao tratamento de efluentes de curtumes.

\section{CONSIDERAÇÕES FINAIS}

O objetivo deste trabalho foi realizar um levantamento sobre o uso do ozônio no tratamento de efluentes de curtume. Verificou-se que diversos estudos vêm sendo realizados, os quais comprovam a eficiência do uso do gás ozônio na remoção de cor, NTK, sólidos suspensos totais e surfactantes, na redução de DQO e no aumento da biodegradabilidade do efluente.

A aplicação do ozônio no tratamento de efluentes de curtume mostra-se uma alternativa ecologicamente correta, pois este é um agente oxidante capaz de reagir com diversas espécies poluentes, não deixando resíduos, já que não produz toxinas na água, e quando não consumido, produz oxigênio $\left(\mathrm{O}_{2}\right)$.

Em um levantamento de campo realizado por Mella et al. (2012) nos curtumes do Estado 


\section{9 a 22 de outubro de 2014 \\ Florianópolis/SC}

do Rio Grande do Sul afim de analisar, caracterizar e comparar as operações unitárias envolvidas no tratamento de efluentes em curtumes observou-se uma similaridade entre os processos empregados nas ETEs (tratamento primário e secundário) e algumas iniciativas isoladas de emprego de tratamento avançado. Pode-se verificar também que os curtumes do estado tem demonstrado interesse crescente em aplicar tratamento avançado em seus efluentes, primeiramente para atingir melhores parâmetros de descarte, tendo em vista a rigorosidade das legislações que estão em vigor, como também, poderão futuramente realizar o reciclo completo de suas águas tratadas empregadas no processo, o que acarretará em uma economia financeira e em uma prática sustentável.

A utilização de ozônio no tratamento de efluentes de curtume é uma técnica promissora. Embora não substitua nenhum dos estágios do tratamento, sua associação com as técnicas atualmente utilizadas pode garantir um efluente tratado com parâmetros de descarte mais próximos dos exigidos pelos órgãos ambientais, ou com características adequadas para reuso no processo.

\section{AGRADECIMENTOS}

Os autores agradecem à FINEP (Chamada Pública MCTI/FINEP CT-HIDRO 01/2013) pelo apoio financeiro a este trabalho, e à CAPES pela concessão das bolsas de doutorado.

\section{REFERÊNCIAS}

ABQTIC - Associação Brasileira dos Químicos e Técnicos da Indústria do Couro, Guia do Couro 2013. ALATON, I. A.; BALCIOGLU, I. A; BAHNEMANN, D. W. Advanced oxidation of a reactive dye bath effluent: comparison of $\mathrm{O}_{3}, \mathrm{H}_{2} \mathrm{O}_{2} / \mathrm{UV}-\mathrm{C}$ and $\mathrm{TiO}_{2} / \mathrm{UV}-\mathrm{A}$ processes. Water Research, v. 36, p. 1143-1154, 2002.

ALMEIDA, E.; ASSALIN, M. R.; ROSA, M. A.; DURÁN, N. Tratamento de Efluentes Industriais por Processos Oxidativos na Presença de Ozônio. Quim. Nova, v. 27, p. 818-824, 2004.

ASSALIN, M. R. e DURÁN, N. Novas tendências para aplicação de ozônio no tratamento de resíduos: ozonização catalítica, Revista Analytica, v. 26, p. 76-86, 2006.

BASSANI, L. Desinfecção de Efluente Sanitário por Ozônio: Parâmetros Operacionais e Avaliação Econômica (Dissertação de Mestrado). Universidade Federal de Santa Catarina, Programa de PósGraduação em Engenharia Ambiental. Florianópolis, 2003.

BOURGIN, M.; ALBET, J.; VIOLLEAU, F. Study of the degradation of pesticides on loaded seeds by ozonation. Journal of Environmental Chemical Engineering, v. 1, p. 1004-1012, 2013.

BOUZID, J.; AYDI, W.; KSIBI, M.; ELEUCH, B. Use of Ozonation Process for the Oxidation of Liming Float Wastewater Stream. Environ. Eng. Sci., v. 25, p. 1139-1147, 2008.

DERCO J.; DUDÁŠ J.; ŠILHÁROVÁ K.; VALIČKOVÁ M.; MELICHER M.; LUPTÁKOVÁ A. Removal of selected micropollutants by ozonation. Chemical Engineering Transactions, v. 29, p. 13151320, 2012.

DI IACONI C.; DEL MORO, G.; DE SANCTIS, M.; ROSSETTI, S. A chemically enhanced biologicalprocess for lowering operative costs and solid residues of industrial recalcitrante wastewater treatment. Water Res., v. 44, p. 3635-3644, 2010.

DI IACONI, C.; RAMADORI, R.; LOPEZ, A. The effect of ozone on tannery wastewater biological treatment at demonstrative scale. Bioresource Technol., v. 100, p. 6121-6124, 2009. 


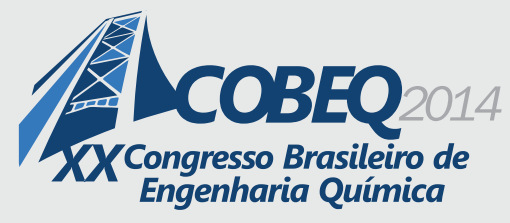

19 a 22 de outubro de 2014

Florianópolis/SC

DOGRUEL, S.; GENCELI, E.A.; BABUNA, F.G.; ORHON, D. Ozonation of non biodegradable organics in tannery wastewater. J. Environ. Sci. Health, v. 7, p. 1705-1715, 2004

FUCK, W. F. e GUTTERRES, M. Produtos químicos perigosos e de uso restrito no couro. Tecnicouro, v. 29, p. 82-89, 2008.

GUTTERRES, M. Curtimento ao Cromo ainda é Predominante. Jornal Exclusivo NH, Novo Hamburgo, p. 10 - 10, 2011.

GUTTERRES, M. e MELLA, B.; Chapter X: Heavy Metals in Water: Presence, Removal and Safety, Book Wastewater Reuse and Management, Editora Springer, Londres, 2014.

HOUSHYAR, Z.; ALI BARADAR KHOSHFETRAT, A. B.; FATEHIFAR, E. Influence of ozonation process on characteristics of pre-alkalized tannery effluents, Chem. Eng. J., v. 191, p. 59- 65, 2012.

INESCOP - Instituto Tecnológico del Calzado y Conexas. Substancias peligrosas que pueden afactar al calzado y sus componestes, 2011.

IUE - International Union of Environment. IUE- 6: Pollution Values from Tannery Processes Under Conditions of Good Practice, 2008. Disponível em: http://www.iultcs.org/pdf/IUE6_2008.pdf

LIU, P.; ZHANG, H.; FENG, Y.; YANG, F.; ZHANG, J. Removal of trace antibiotics from wastewater: A systematic study of nanofiltration combined with ozone-based advanced oxidation. Chem. Eng. J., v. 240 , p. 211-220, 2014.

LOFRANO, G.; MERIÇ, S.; ZENGIN, G. E.; ORHON, D. Chemical and biological treatment technologies for leather tannery chemicals and wastewaters: A review. Sci. Total Environ., v. 461-462, p. 265-281, 2013.

MELlA, B.; BORDIGNON, S.; QUADROS, A. V.; GUTTERRES, M., 2012, Avaliação QualiQuantitativa das Operações Unitárias envolvidas nas Estações de Tratamento de Efluentes em Curtumes do Estado do RGS. XVIII Congreso de la Federación Latino Americana de Químicos y Técnicos de la Industria del Cuero - FLAQTIC.

PÉREZ, M.; TORRADES, F.; DOMÈNECH, X.; PERAL, J. Treatment of bleaching Kraft mil effluents and polychlorinated phenolic compounds with ozonation. J. Chem. Technol. Biotechnol., v.77, p. 891897, 2002.

PREETHI, V.; KALYANI, K. S. P.; IYAPPAN, K.; SRINIVASAKANNAN, C.; BALASUBRAMANIAM, N. ; VEDARAMAN, N. Ozonation of tannery effluent for removal of cod and color, J. Hazard. Mater., v. 166 , p. 150-154, 2009.

SCHRANK, S.G.; JOSÉ, H.J.; MOREIRA, R.F.P.M.; SCHRODER H.F. Elucidation of the behaviour of tannery wastewater under advanced oxidation conditions. Chemosphere, v.56, p.411-423, 2004.

SRINIVASAN, S.V.; REMA, T.; CHITRA, K.; SRI BALAKAMESWARI, K.; SUTHANTHARARAJAN, R.; UMA MAHESWARI, B.; RAVINDRANATH, E.; RAJAMANI, S. Decolourisation of leather dye by ozonation. Desalination, v. 235, p. 88-92, 2009.

SUTHANTHARARAJAN, R.; RAVINDRANATH, E.; CHITRA, K.; UMAMAHESWARI, B.; RAMESH, T.; RAJAMANI, S. Membrane application for recovery and reuse of water from treated tannery wastewater. Desalination, v. 164, p. 151-156. 2004.

VON GUNTEN, U. Ozonation of drinking water: Part I. Oxidation kinetics and product formation. Water Res., v. 37, p. 1443-1467, 2003.

WEGNER, B. Alquilfenol etoxilado - Um problema Europeu? Revista do Couro, v. 170, p. 64-69, 2004. 